\title{
Interferência dos ácidos graxos ômega-3 nos lipídeos sangüíneos de ratos submetidos ao exercício de natação
}

\author{
Omega-3 fatty acids interference on the blood \\ lipids of rats subjected to swimming exercise
}

Bettina MORITZ1

Elisabeth WAZLAWIK' ${ }^{1}$

Jaqueline MINATTI2

Rafaella Cristina DIMBARRE DE MIRANDA²

\section{RE S U M O}

\section{Objetivo}

Investigar os efeitos da suplementação com ácidos graxos ômega-3, nas doses de 0,5 e 1,0 g/ $\mathrm{kg} / \mathrm{dia}$, nos lipídeos sangüíneos de ratos submetidos ou não ao protocolo do nado.

\section{Métodos}

Ratos Wistar foram divididos em grupos: controle, controle+nado, ácidos graxos ômega-3 e ácidos graxos ômega-3+nado. Os ácidos graxos ômega-3 e ácidos graxos ômega-3+nado receberam suplementação; os demais receberam água por gavagem. Os controle+nado e ácidos graxos ômega-3+nado foram submetidos ao exercício. Foram avaliadas as concentrações plasmáticas de colesterol total, triglicérides e lipoproteína de alta densidade, antes e após os procedimentos experimentais.

\section{Resultados}

No protocolo de $0,5 \mathrm{~g} / \mathrm{kg} / \mathrm{dia}$, em relação às concentrações de colesterol total, foi observada redução significativa proporcionalmente maior no grupo ácidos graxos ômega-3+nado, apesar de o grupo controle+nado e o ácidos graxos ômega-3 também terem apresentado diminuição. No ensaio de 1,0g/kg/dia todos os grupos apresentaram uma diminuição que foi maior, respectivamente, no ácidos graxos ômega-3+nado e, a seguir, no ácidos graxos ômega-3. Quanto aos triglicérides, foram encontradas reduções em todos os grupos experimentais, que foi maior no grupo ácidos graxos ômega-3+nado, do protocolo de 0,5g/kg/dia, enquanto que no de 1,0 g/ $/ \mathrm{kg} / \mathrm{dia}$ a diminuição foi significativa apenas nos grupos ácidos graxos ômega-3 e ácidos graxos

\footnotetext{
1 Universidade Federal de Santa Catarina, Centro de Ciências da Saúde, Programa de Pós-Graduação em Nutrição. Campus Universitário, Trindade, 88040-900, Florianópolis, SC, Brasil. Correspondência para/Correspondence to: B. MORITZ. E-mail: $<$ bettina@bettinamoritz.com.br>

2 Universidade Federal de Santa Catarina, Curso de Nutrição. Bolsistas do Programa Institucional de Bolsas de Iniciação Científica-CNPq e de Iniciação à Pesquisa BIP-UFSC, respectivamente. Florianópolis, SC, Brasil.
} 
ômega-3+nado. Quanto ao HDL, no protocolo de $0,5 \mathrm{~g} / \mathrm{kg} /$ dia foi encontrado aumento nos animais que não foram suplementados, enquanto que em todos os grupos de $1,0 \mathrm{~g} / \mathrm{kg} / \mathrm{dia}$ houve uma diminuição do HDL.

\section{Conclusão}

A suplementação com ácidos graxos ômega-3 nas doses 0,5 ou 1,0 $/ \mathrm{kg} / \mathrm{dia}$, associada ao nado, reduzem as concentrações plasmáticas de colesterol total e triglcérides, mas estudos adicionais, também com outras doses, são necessários para a compreensão da relação entre a ingestão de óleo de peixe e as concentrações de lipídeos sangüíneos.

Termos de indexação: Ácido graxo ômega-3. Lipídeos. Natação. Ratos.

\section{A B S T R A C T}

\section{Objective}

To investigate the effects of omega-3 fatty acid supplementation at doses of 0.5 and $1.0 \mathrm{~g} / \mathrm{kg} / \mathrm{day}$ on the blood lipids of rats submitted or not to swimming exercise.

\section{Methods}

Wistar rats were divided into the following groups: control, control+swimming, omega-3 fatty acids and omega-3 fatty acids+swimming. The omega-3 fatty acids and omega-3 fatty acids+swimming groups received supplements by gavage, while the remaining animals received water by the same method. The control+swimming and omega-3 fatty acids +swimming groups were submitted to exercise. Plasma concentrations of total cholesterol, triglycerides and HDL were determined before and after the experimental procedures.

\section{Results}

The concentrations of total cholesterol in the $0.5 \mathrm{~g} / \mathrm{kg} /$ day groups reduced proportionally more in the omega-3 fatty acids+swimming group, even though total cholesterol of the control+swimming and omega-3 fatty acids groups also decreased. Total cholesterol decreased in both groups receiving $1.0 \mathrm{~g} / \mathrm{kg} / \mathrm{day}$ supplementation, but the decrease was higher in the omega-3 fatty acids+swimming group than in the omega-3 fatty acids group. Triglycerides also decreased in all experimental groups. The greatest decrease was seen in the omega-3 fatty acids+swimming group receiving $0.5 \mathrm{~g} / \mathrm{kg} /$ day supplementation. In the $1.0 \mathrm{~g} / \mathrm{kg} / \mathrm{day}$ protocol, the decrease was significant in both groups: the omega-3 fatty acids and omega-3 fatty acids+swimming groups. HDL increased among the non-supplemented animals and decreased among the animals receiving a supplementation of $1.0 \mathrm{~g} / \mathrm{kg} /$ day.

\section{Conclusion}

Omega-3 fatty acid supplementation at doses of 0.5 or $1.0 \mathrm{~g} / \mathrm{kg} / \mathrm{day}$ associated with swimming exercise reduced plasma concentrations of total cholesterol and triglycerides, yet additional studies, including varying doses, are necessary to better understand the relationship between ingestion of fish oil and blood lipid concentrations.

Indexing terms: Fatty acid, Omega-3. Lipids. Swimming. Rats.

\section{N T R O D U Ç Ã O}

Os ácidos graxos ômega-3 ( $\omega$-3), obtidos pela dieta alimentar, são essenciais à saúde humana e não podem ser sintetizados em tecidos de mamíferos. Estudos sugerem que o consumo adequado desses $\omega$-3 esteja relacionado à prevenção de doenças cardiovasculares, sendo proposto que possam melhorar o perfil lipídico plasmático ${ }^{1-3}$, beneficiar pacientes com arritmias cardíacas, diminuir processos inflamatórios, apresentar propriedades antitrombóticas ${ }^{4}$ e efeitos antiateroscleróticos ${ }^{5}$; são ainda importantes na prevenção do desenvolvimento da síndrome plurimetabólica6.

Sugere-se que os hábitos relacionados ao estilo de vida, como as dietas desequilibradas nutricionalmente (por exemplo, ricas em gordura saturada, trans, colesterol e pobres em fibras, gorduras poliinsaturadas e monoinsaturadas) e o sedentarismo, são fatores de risco para o desenvolvimento de doenças cardiovasculares ${ }^{7}$. Baró et 
al. ${ }^{8}$ consideram que são vários os fatores de risco influenciados pela má alimentação e associados às doenças cardiovasculares, ressaltando a concentração aumentada de colesterol total e LDL e baixas concentrações de HDL.

A relação entre os lipídeos e as doenças cardiovasculares tem sido estudada desde 1847, quando Vogel detectou a presença de colesterol nas placas de ateroma ${ }^{7}$. O desequilíbrio no metabolismo lipídico parece predispor ao desenvolvimento da aterosclerose, e os fatores dietéticos, como dietas ricas em gordura saturada, trans ou colesterol, desempenham um papel importante, pois podem proporcionar a progressão da doença ${ }^{8}$.

É sabido que as dietas que contêm altas concentrações de gorduras saturadas e colesterol aumentam significativamente as concentrações de colesterol total e LDL e estão relacionadas com o aumento da incidência de infarto do miocárdio, devido à sua relação com o aumento do colesterol sérico ${ }^{9}$. Foi observado que, quando esses ácidos graxos saturados (AGS) são substituídos na dieta por ácidos graxos poliinsaturados (AGPI) ou monoinsaturados (AGMI) ocorre uma melhora no perfil lipídico, o que, por sua vez, pode ter um efeito benéfico sob o ponto de vista cardiovascular. Atualmente, têm merecido destaque os efeitos do $\omega$-3 sobre a função cardiovascular ${ }^{10-11}$, havendo ainda, no entanto, considerável controvérsia concernente à relativa importância dos AGPI na prevenção de doenças cardiovasculares.

Além disso, estudos desenvolvidos em seres humanos e animais têm revelado uma associação negativa entre a ingestão de AGMI e AGPI e a incidência de doenças cardiovasculares ${ }^{7}$. Entretanto, nos trabalhos realizados com óleo de peixe e azeite de oliva, fontes de $\omega$-3 e ômega-9, respectivamente, parecem ter havido efeitos positivos com o seu consumo, como nas dislipidemias e nas arritmias. Por outro lado, o consumo excessivo de óleos ricos em ácido linoléico ( $\omega$-6) ou AGS não é recomendável, por apresentarem efeitos pró-inflamatórios, pró-trombóticos e pró-aterogênicos ${ }^{4}$.
Atualmente, a população ocidental apresenta uma dieta com elevado consumo de AGS e $\omega$-6. Tem-se sugerido que esse padrão alimentar pode reduzir a eficiência do ácido alfa-linolênico $(\omega-3)$, e as grandes proporções de AGS e/ou $\omega$-6 poderiam interferir na eficácia da conversão do $\omega$-3 em ácido eicosapentanóico (EPA) e ácido docosahexanóico (DHA) ${ }^{12}$.

Por outro lado, alguns estudos demonstraram um aumento na peroxidação lipídica e um aumento na produção de radicais livres quando consumidas maiores quantidades de AGPI, comparadas ao consumo elevado de AGMI ou AGS. Além disso, considera-se que aumentos significativos na peroxidação lipídica da parede arterial e aumento nas concentrações de LDL, com conseqüente comprometimento da função endotelial possam favorecer o desenvolvimento da aterosclerose $^{13}$. A prática de exercícios físicos também tem sido apontada como essencial na prevenção de doenças cardiovasculares. É preconizado que os exercícios físicos praticados na intensidade leve a moderada possam beneficiar os indivíduos, destacando-se o fato de propiciarem a diminuição da adiposidade corporal e a melhora do perfil lipídico dos indivíduos ${ }^{14}$, além de contribuírem com o sistema de defesa antioxidante ${ }^{15}$.

Portanto, a prática regular de exercícios físicos e o consumo de dietas adequadas podem auxiliar na prevenção ou na progressão de doenças cardiovasculares $^{16}$. O objetivo deste trabalho foi investigar os efeitos da suplementação de $\omega$-3 nos lipídeos sangüíneos de ratos submetidos ou não ao protocolo do nado.

\section{MÉ TOD OS}

Foram utilizados Rattus novergicus da linhagem Wistar - sendo 88 machos, com 1 1 1/2 mês de idade e peso entre $150 \mathrm{~g}$ a $200 \mathrm{~g}$, obtidos do Biotério Central da Universidade Federal de Santa Catarina (UFSC). Os animais foram transferidos para o biotério setorial do Laboratório de Nutrição Clínica, da UFSC, e, acondicionados em 5 ou 6 animais, por caixa plástica $(42 \mathrm{~cm} \times 34 \mathrm{~cm} \times$ 
$17 \mathrm{~cm})$, e mantidos em ambiente com temperatura controlada $\left(22^{\circ} \mathrm{C}\right.$ desvio-padrão $\left.-\mathrm{DP}=2^{\circ} \mathrm{C}\right)$, com ciclo alternado de claro/escuro de 12 horas. A dieta comercial e a água foram oferecidas ad libidum até momentos antes das condições experimentais.

Os ensaios biológicos foram realizados de acordo com o Guia de Uso e Cuidados com Animais Laboratoriais do Colégio Brasileiro de Experimentação Animal (COBEA) e o protocolo experimental foi aprovado pela Comissão de Ética para o Uso de Animais da Universidade Federal de Santa Catarina (CEUA n 280/04).

\section{Tratamento com ácido graxo ômega-3}

Foi utilizado o $\omega$-3, da marca Phytomare ${ }^{\circledR}$, contendo $0,141 \mathrm{mg}$ de $\omega$-3, sendo $2 / 3$ de EPA, $1 / 3$ de DHA e 20mg de vitamina E. A quantidade administrada de $\omega$-3 ou água a cada rato foi relacionada com o peso do animal, e os diferentes grupos receberam 0,5 ou $1,0 \mathrm{~g} / \mathrm{kg}$ de peso, durante o período de 28 dias. As cápsulas foram doadas pelo professor Dr Luis Beirão, do Departamento de Tecnologia de Alimentos (CCAVUFSC).

\section{Grupos experimentais}

a) Grupo controle: tratado por gavagem com água e não submetido ao protocolo do nado.

b) Grupo controle+nado: tratado por gavagem com água e submetido ao protocolo do nado.

c) Grupo $\omega$-3: tratado por gavagem com $\omega$-3 e não submetido ao protocolo do nado.

d) Grupo $\omega-3$ + nado: tratado por gavagem com $\omega$-3 e submetido ao protocolo do nado.

\section{Protocolo do nado}

Os ratos foram submetidos ao modelo do nado proposto inicialmente por Porsolt et al. ${ }^{17} \mathrm{e}$ colocados individualmente em cilindros plásticos (altura $=46 \mathrm{~cm}$, diâmetro $=20 \mathrm{~cm}$ ), contendo $38 \mathrm{~cm}$ de água. Os animais foram submetidos ao exercício de nado de intensidade leve (sem sobrecarga) por 28 dias, 5 horas após a administração de $\omega$-3 ou água, por gavagem. Nos três primeiros dias, os ratos permaneceram por 10 minutos na água, para adaptação ao meio ${ }^{18}$ e após, do $4^{\circ}$ ao $28^{\circ}$ dia, foram submetidos ao nado por 20 minutos. Durante a sessão de nado os animais foram observados um a um e a cada momento que flutuavam, eram estimulados imediatamente a reiniciar o nado. A cada sessão de nado, a água foi trocada para cada animal. A água na qual os animais foram mantidos para nadar apresentava temperatura de $27^{\circ} \mathrm{C}\left(\mathrm{DP}=1^{\circ} \mathrm{C}\right)^{18}$ para diminuir o estresse provocado por temperaturas superiores ou inferiores à ambiente.

\section{Coleta de sangue}

No tempo zero, isto é, uma semana antes de serem iniciados o tratamento e o protocolo do nado e após o término desses procedimentos experimentais ( $28^{\circ}$ dia de tratamento e/ou nado), os animais foram submetidos ao jejum de 12 horas. Após esse período, o sangue foi coletado por punção cardíaca, estando os animais anestesiados com éter etílico. Foi coletado, aproximadamente, $1 \mathrm{~mL}$ de sangue de cada rato, com agulhas descartáveis de $25 \times 7 \mathrm{~mm}$ e seringas de $5 \mathrm{~mL}$. Cada amostra de sangue foi colocada em um tubo de ensaio com heparina (1 gota) e, em seguida, centrifugada. O plasma foi separado com pipeta, acondicionado em eppendorf e colocado em freezer para posterior análise.

\section{Análise bioquímica do sangue}

A avaliação das concentrações plasmáticas de triglicerídeos, colesterol total e HDL ocorreu antes e após os procedimentos experimentais com os ratos. No tempo zero, antes do início da administração de $A G \omega$-3 e do protocolo do nado, foi feito um pareamento dos animais, de modo que os diferentes grupos experimentais apresentassem 
valores médios de colesterol total, triglicerídeos e HDL semelhantes.

A análise bioquímica do sangue foi realizada com o auxílio de máquina automatizada da marca Cobas ${ }^{\circledR}$ Mira e verificada a absorbância dos analitos. Para a análise dos triglicerídeos e colesterol total foram pipetados $100 \mu \mathrm{L}$ do soro, acondicionados em eppendorf e colocados na máquina para análise.

Para a determinação do HDL foram adicionados $100 \mu \mathrm{L}$ de soro e $100 \mu \mathrm{L}$ de precipitante nos tubos de ensaio. As substâncias foram agitadas e centrifugadas a 4000rpm durante 15 minutos, para obter um sobrenadante límpido. Esse sobrenadante límpido foi pipetado imediatamente após a centrifugação e foi acondicionado em eppendorf para avaliação automatizada. Para a análise de todos os parâmetros bioquímicos foram utilizados reagentes da marca Labtest ${ }^{\circledR}$. Esse procedimento foi realizado no Laboratório de Análises Clínicas Genesis ${ }^{\circledR}$, sob supervisão do farmacêuticobioquímico Fernando Pirolli.

\section{Análise estatística}

Os dados obtidos foram avaliados pelo teste t de Student pareado, com nível de significância $p<0,05$. Para avaliação dos dados foi utilizado o software INSTAT versão 3.01.

\section{RESULTA DOS}

\section{Colesterol total}

Com relação ao experimento em que foi administrado $0,5 \mathrm{~g} / \mathrm{kg} /$ dia de $\omega-3$, a análise dos resultados demonstrou uma redução estatisticamente significante nas concentrações plasmáticas de colesterol total nos grupos: controle+nado $(p=0,003), \omega-3(p=0,0015)$, e no grupo $\omega-3+$ nado $(p<0,0001)$, quando foram comparados os valores iniciais aos valores finais de cada grupo, pelo do teste $t$. O grupo controle, não submetido ao nado, não apresentou diferença significante. A comparação dos resultados na dose de 0,5g/ $\mathrm{kg} / \mathrm{dia}$, antes e ao final do experimento, pode ser visualizada na Figura 1.

No experimento no qual foi utilizada a dose de 1,0g/kg/dia de $\omega$-3 observou-se uma redução significante das concentrações de colesterol total em todos os grupos experimentais entretanto, as mais expressivas foram apresentadas pelos grupos $\omega$-3 e $\omega$-3+nado, com $p<0,0001$ (Figura 2).

\section{Triglicerídeos}

No experimento no qual foi utilizado 0,5g/kg/dia de $\omega$-3, observou-se redução significante nas concentrações plasmáticas de triglicerídeos em todos os grupos: grupo controle $(p=0,002)$, grupo controle+nado $(p=0,008)$, grupo $\omega$-3 $(p=0,0015)$ e grupo $\omega$-3+nado $(p<0,0001)$ (Figura 3).

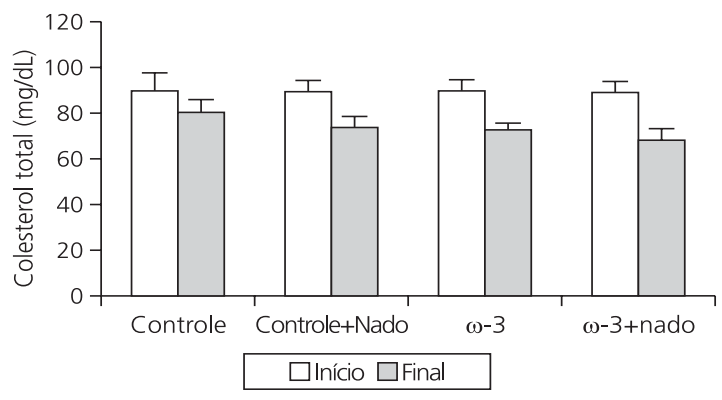

Figura 1. Concentrações plasmáticas de colesterol total, antes (início) e após (final) os procedimentos experimentais, para avaliar o efeito da administração de ácidos graxos $\omega-3$, por gavagem, na dose de 0,5g/kg/dia ou água, de ratos submetidos ou não ao protocolo do nado por 28 dias. Grupo controle, que recebeu água por gavagem e não foi submetido ao protocolo do nado; Grupo controle+nado, que recebeu água por gavagem e foi submetido ao protocolo do nado; Grupo $\omega$-3, não submetido ao nado; Grupo $\omega$-3+nado, tratado com ácido graxo $\omega$-3 e submetido ao nado. Os resultados são expressos como média \pm erro-padrão de 11-12 animais por grupo. ${ }^{*} p<0,05$ comparado ao início (teste $t$ de Student). 


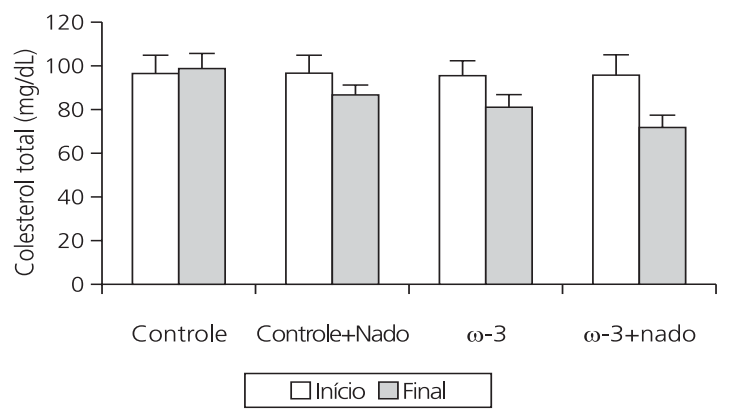

Figura 2. Concentrações plasmáticas de colesterol total (mg/dl), antes (início) e após (final) os procedimentos experimentais, para avaliar o efeito da administração de ácido graxo $\omega-3$, por gavagem, na dose $1,0 \mathrm{~g} / \mathrm{kg} / \mathrm{dia}$ ou água, em ratos submetidos ou não ao protocolo do nado por 28 dias. Grupo controle, que recebeu água por gavagem e não foi submetido ao protocolo do nado; Grupo controle+nado, que recebeu água por gavagem e foi submetido ao protocolo do nado; Grupo $\omega-3$, não submetido ao nado; Grupo $\omega-3+$ nado, tratado com ácido graxo $\omega$-3 e submetido ao nado. Os resultados são expressos como média e erro-padrão de 10-11 animais por grupo. * $p<0,05$ comparado ao início (teste $t$ de Student).

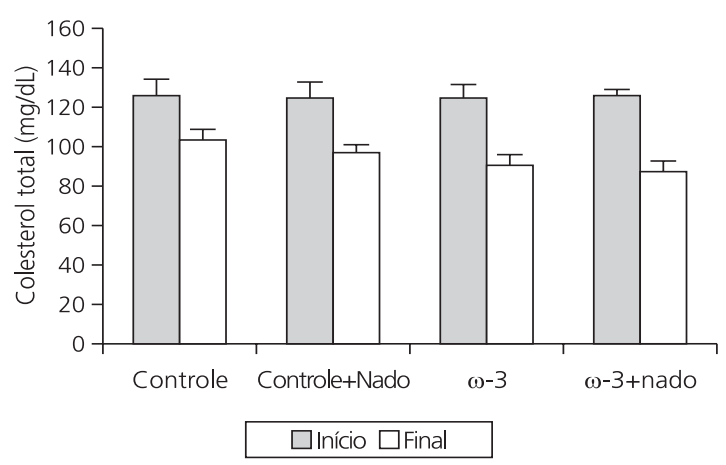

Figura 3. Concentrações plasmáticas de triglicerídeos (mg/dl), antes (início) e após (final) os procedimentos experimentais, para avaliar o efeito da administração de ácido graxo $\omega-3$, por gavagem, na dose de $0,5 \mathrm{~g} / \mathrm{kg} /$ dia ou água, de ratos submetidos ou não ao protocolo do nado por 28 dias. Grupo controle, que recebeu água por gavagem e não foi submetido ao protocolo do nado; Grupo controle+nado, que recebeu água por gavagem e foi submetido ao protocolo do nado; grupo $\omega$-3 não submetido ao protocolo do nado; Grupo $\omega-3+$ nado, que recebeu ácidos graxos $\omega-3$ por gavagem e foi submetido ao nado.
Já quando os grupos experimentais do protocolo com $1,0 \mathrm{~g} / \mathrm{kg} / \mathrm{dia}$ de $\omega$-3 foram submetidos ao teste $t$, com a intenção de comparar os valores obtidos para triglicerídeos no tempo zero e após 28 dias de tratamento, observouse uma redução significante apenas nos grupos $\omega-3(p=0,0463)$ e $\omega-3+$ nado $(p=0,0065)$ (Figura $4)$.

\section{HDL}

No experimento no qual foi utilizado o tratamento de $1,0 \mathrm{~g} / \mathrm{kg} / \mathrm{dia}$ de $\omega$-3 ou água, quando comparados os valores iniciais aos finais por meio do teste $t$, foram observadas reduções significantes em todos os grupos experimentais.

Já no experimento em que os animais foram tratados com 0,5g/kg/dia de $\omega$-3, os grupos experimentais controle e controle+nado apresentaram aumento significante nas concentrações plasmáticas de HDL, com significância $p=0,0124$ e $p=0,0087$, respectivamente (Tabela 1).

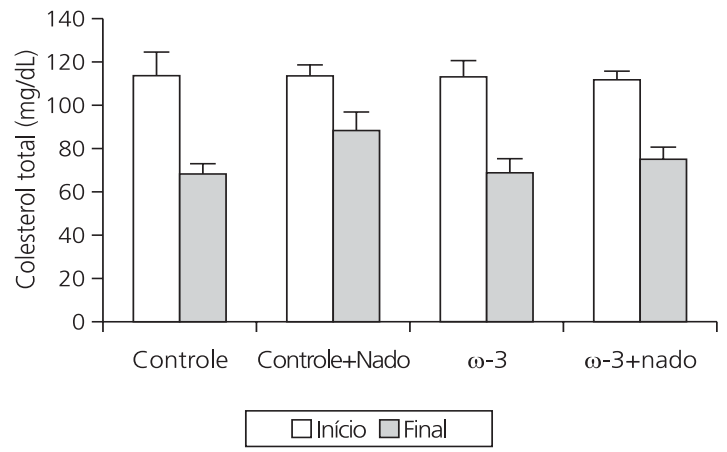

Figura 4. Concentrações plasmáticas de triglicerídeos, antes (início) e após (final) os procedimentos experimentais, para avaliar o efeito da administração de ácido graxo $\omega-3$, por gavagem, na dose de $1,0 \mathrm{~g} / \mathrm{kg} / \mathrm{dia}$ ou água, de ratos submetidos ou não ao protocolo do nado por 28 dias. Grupo controle, que recebeu água por gavagem e não foi submetido ao protocolo do nado; Grupo controle+nado, que recebeu água por gavagem e foi submetido ao protocolo do nado; Grupo $\omega-3$ não submetido ao protocolo do nado; Grupo $\omega$ $3+$ nado, que recebeu ácidos graxos $\omega$-3 por gavagem e submetido ao nado. Os resultados são expressos como média \pm erro-padrão de 10-11 animais por grupo ${ }^{*} p<0,05$ comparado ao início (teste $t$ de Student). 
Tabela 1. Concentrações plasmáticas de HDL-colesterol $(\mathrm{mg} / \mathrm{dl})$ de ratos submetidos à administração, por gavagem, de ácidos graxos $\omega-3$, na dose de $0,5 \mathrm{~g} / \mathrm{kg} / \mathrm{dia}$ ou $1,0 \mathrm{~g} / \mathrm{kg} / \mathrm{dia}$ ou água e submetidos ou não ao protocolo do nado, durante 28 dias.

\begin{tabular}{|c|c|c|c|c|c|c|c|c|}
\hline \multirow{3}{*}{ Grupos experimentais } & \multicolumn{4}{|c|}{$0,5 \mathrm{~g} / \mathrm{kg} / \mathrm{dia}$} & \multicolumn{4}{|c|}{$0,1 \mathrm{~g} / \mathrm{kg} / \mathrm{dia}$} \\
\hline & \multicolumn{2}{|c|}{ Início } & \multicolumn{2}{|c|}{ Final } & \multicolumn{2}{|c|}{ Início } & \multicolumn{2}{|c|}{ Final } \\
\hline & $M$ & EPM & $\mathrm{M}$ & EPM & $\mathrm{M}$ & EPM & $\mathrm{M}$ & EPM \\
\hline Basal & 40,50 & 2,63 & 66,1 & 5,83 & 54,0 & 5,40 & 39,6 & 5,83 \\
\hline Controle & 40,50 & 2,45 & 52,5 & 3,28 & 46,5 & 3,00 & 32,6 & 2,14 \\
\hline Controle + nado & 39,96 & 2,32 & 49,0 & 3,44 & 55,7 & 4,51 & 32,5 & 1,58 \\
\hline$\omega-3$ & 40,40 & 3,09 & 47,5 & 2,63 & 60,1 & 2,41 & 29,3 & 1,42 \\
\hline$\omega-3+$ nado & 40,90 & 2,68 & 41,2 & 2,55 & 44,7 & 5,11 & 29,4 & 1,80 \\
\hline
\end{tabular}

* $p<0,05$, comparado ao início do respectivo protocolo (0,5 ou 1,0g/kg/dia de $\omega-3)$; M: média; EPM: erro-padrão.

\section{DIS C U S S Ã O}

Diversos autores sugerem que dietas acrescidas de $\omega$-3 poderiam melhorar o perfil lipídico, tanto em humanos quanto em animais e, conseqüentemente, reduzir o risco de desenvolvimento de doenças cardiovasculares ${ }^{10-11}$. Na confrontação com a literatura, os resultados obtidos são por vezes contraditórios, destacando-se a diminuição das concentrações plasmáticas de triglicerídeos ${ }^{1}$, de colesterol total ${ }^{2-3}$ ou de ambas ${ }^{10}$.

Em relação às concentrações plasmáticas de colesterol total foi observada uma diminuição significante $(p<0,0001)$ no grupo que foi suplementado com 0,5g/kg/dia de $\omega$-3 e submetido ao exercício físico, em relação ao valor inicial encontrado. Entretanto, os grupos controle+nado e $\omega$-3 também demonstraram redução significante.

Ao analisar os valores finais em relação aos iniciais, houve uma maior diferença no grupo $\omega-3$, com $p=0,0015$, enquanto que no grupo controle+nado essa redução foi menor com valor de $p=0,003$. Ou seja, a suplementação de $\omega-3$, na dose de $0,5 \mathrm{~g} / \mathrm{kg} / \mathrm{dia}$ pareceu indicar um maior impacto do que a prática do nado na redução das concentrações plasmáticas de colesterol total. Isto se deve, provavelmente, ao fato de que o exercício utilizado tenha sido de intensidade leve (sem sobrecarga), priorizando-se a freqüência de exercício (volume). Exercícios de intensidade leve a moderada parecem ser suficientes na redução da adiposidade corporal e na melhora do perfil lipídico de indivíduos ${ }^{14}$. Talvez, se o exercício físico utilizado priorizasse intensidade e volume de treinamento, com o intuito de treinamento aeróbico, resultados mais significativos poderiam ser encontrados nos grupos submetidos ao nado.

No experimento realizado com 1,0g/kg/dia de $\omega$-3, todos os grupos apresentaram redução das concentrações plasmáticas de colesterol total quando o valor final foi comparado ao inicial (tempo zero). Os grupos $\omega$-3 e $\omega$-3+nado apresentaram maior redução $(p<0,0001)$ das concentrações plasmáticas de colesterol total.

Conforme referido, em ambos os protocolos os animais suplementados com $\omega$-3 apresentaram redução das concentrações plasmáticas de colesterol total, comparando-se os valores finais aos iniciais (tempo zero). Destaca-se que as reduções foram maiores quando a suplementação foi associada ao exercício físico (nado), mesmo sendo este de intensidade leve. Pode isso sugerir um sinergismo da suplementação do óleo de peixe com o nado.

Morvan et al. ${ }^{19}$ observaram redução na concentração plasmática de colesterol total em camundongos fêmeas tratadas por 16 semanas com 8,33\% de lipídeos, sendo 5,00\% advindos da ração comercial e 3,33\% de $\omega$-3 (EPA + DHA) comparado ao grupo controle, que recebeu somente ração comercial. Apesar de o teor de lipídeos utilizados e neste estudo, quando associado à suplementação com $\omega$-3 $(6,30 \%$ ou $7,80 \%$, nos protocolos de 0,5 e 1,0 $/ \mathrm{gg} / \mathrm{dia}$, respectivamente), ser inferior ao utilizado por Morvan et al. ${ }^{19}$, também se constataram reduções 
nas concentrações plasmáticas de colesterol total, independentemente da prática do nado. Isto porque os grupos $\omega-3$ apresentaram reduções maiores do que os demais grupos nas concentrações plasmáticas de colesterol total (com uma redução de $27,00 \%$ e 19,80\% nos protocolos de 0,5 e 1,0 $/ \mathrm{kg} / \mathrm{dia}$, respectivamente) do que os grupos controle+nado, que apresentaram redução de $22,78 \%$ no protocolo de $0,5 \mathrm{~g} / \mathrm{kg} /$ dia e $17,41 \%$ no protocolo de $1,0 \mathrm{~g} / \mathrm{kg} / \mathrm{dia}$.

As concentrações plasmáticas elevadas de triglicerídeos também têm sido associadas a um maior risco de doenças coronarianas. Esses triglicerídeos são encontrados predominantemente nas lipoproteínas de muito baixa densidade (VLDL). Alguns estudos têm sugerido que dietas ricas em óleo de peixe possam reduzir as concentrações plasmáticas de triglicerídeos, tanto em pessoas ou animais com hipertrigliceridemia ${ }^{10,20}$, quanto em normolipidêmicos ${ }^{1,12,19}$.

Verificou-se que com a ingestão média de $0,55 \mathrm{~g}$ de óleo de peixe contendo $0,157 \mathrm{~g}$ de $\mathrm{EPA}+\mathrm{DHA}$ (dose de $0,5 \mathrm{~g} / \mathrm{kg} / \mathrm{dia}$ de $\omega$-3), quando comparados os valores finais aos iniciais (tempo zero) pelo teste $t$, todos os grupos reduziram as concentrações plasmáticas de triglicerídeos, e a redução mais significante foi encontrada no grupo submetido ao exercício físico e suplementado com óleo de peixe $(p<0,0001)$.

Já no protocolo de 1,0g/kg/dia, quando se comparou a concentração inicial e final de triglicerídeos, foram observadas reduções significantes apenas nos grupos $\omega$-3 $(p=0,046)$ e $\omega$-3+nado $(p=0,0065)$. Portanto, a suplementação com $\omega-3$ pode ter contribuído para a redução nas concentrações plasmáticas de triglicerídeos.

Em relação à possível interferência de $\omega$-3 nos lipídeos sangüíneos, Jorge et al. ${ }^{13}$ observaram uma redução de $31 \%$ na concentração de triglicerídeos plasmático de coelhos hipercolesterolêmicos suplementados com apenas $300 \mathrm{mg} / \mathrm{kg} /$ dia de $\omega$-3, por 15 dias, comparados àqueles não suplementados. Destaca-se que todos os animais foram submetidos ao tratamento com dieta hipercolesterolêmica, composta por ração comer- cial adicionada de $0,5 \%$ de colesterol $+2,0 \%$ de gordura de coco (rica em AGS), 15 dias antes do início da suplementação com $\omega-3$, sendo esta mantida por todo o experimento.

Hipóteses sobre o mecanismo pelo qual os ácidos graxos poliinsaturados são responsáveis pela diminuição das concentrações de colesterol total estão sendo consideradas, propondo-se que os AGPI podem ser responsáveis pelo aumento da excreção de colesterol sob a forma de ácidos biliares, redistribuindo, dessa forma, as concentrações no plasma e tecidos; ou pelo aumento de receptores do fígado de $L D L$, levando a uma diminuição na sua concentração plasmática ${ }^{21}$.

Também é sugerido que os $\omega$-3 são capazes de inibir a síntese de trigilicerídeos no fígado ${ }^{19}$ e/ou acelerar o catabolismo de VLDL e quilomícrons, pelo aumento da atividade da enzima lípase lipoprotéica (LPL) ${ }^{22-23}$, o que poderia resultar em uma menor concentração plasmática de TG, principalmente no estado pós-prandial.

Outra proposta está relacionada à ApoB100, uma partícula que serve como porção ligante para o receptor das lipoproteínas e está intimamente relacionada com a síntese endógena de $V_{L D L}{ }^{24}$. Pan et al. ${ }^{25}$ propuseram que os $\omega-3$ são capazes de estimular uma nova via de degradação da ApoB100, por meio da elevação da recaptação dessa lipoproteína pelo fígado. Esse mecanismo parece requerer um aumento da peroxidação lipídica, uma vez que, conforme observaram os autores, a adição de antioxidante (vitamina E) ao tratamento com $\omega-3$ resultou na diminuição na peroxidação lipídica, assim como na menor degradação da ApoB100 recémsintetizada. Os resultados deste estudo sugeriram que a peroxidação lipídica pode favorecer a redução dos lipídeos sangüíneos, visto que, com o aumento da recaptação da ApoB100 recémsintetizada, menores quantidades de partículas de VLDL poderiam ser produzidas, reduzindo assim as concentrações de colesterol total e triglicerídeos no plasma. Por outro lado, existem fortes evidências de que o aumento do estresse oxidativo possa aumentar e levar a uma maior concentração de 
LDL oxidada, propiciando uma possível evolução da aterosclerose ${ }^{26}$. Foi proposto ainda que o aumento do estresse oxidativo poderia também induzir a danos no DNA do hepatócito ${ }^{27}$.

Além disso, tem sido sugerido que dietas ricas em $\omega$-3 podem diminuir a concentração de vitamina E no plasma, fígado e rim de animais, o que levaria a um aumento na formação de radicais livres, pela diminuição na proteção, pois a vitamina E é responsável pela neutralização desses radicais $^{28}$. Sugere-se que a redução nas concentrações de antioxidantes e o aumento na formação de radicais livres possam estimular efeitos deletérios no sistema cardiovascular7,13,22. Portanto, outros estudos adicionais devem ser realizados no intuito de investigar as verdadeiras necessidades de antioxidantes (especialmente a vitamina E) para indivíduos alimentados com uma dieta rica em $\omega-3$, pois parece ser de suma importância uma adequada ingestão de macro e micronutrientes para a potencialização dos efeitos benéficos do $\omega-3$.

Segundo Mata et al. ${ }^{29}$, dietas ricas em $\omega$-3 também poderiam reduzir as concentrações plasmáticas de HDL. Não estão bem estabelecidos quais os mecanismos responsáveis por essa redução - são sugeridas modificações nos receptores das lipoproteínas, nas membranas celulares e em algumas enzimas relacionadas com o metabolismo da HDL, envolvidos na transferência de colesterol.

Morvan et al. ${ }^{19}$ suplementaram camundongos com 3,33\% de AG $\omega-3$, provenientes de óleo de peixe, por 16 semanas e observaram uma redução nas concentrações plasmáticas de HDL e um aumento das concentrações de éster de HDL no fígado, quando comparados ao grupo não tratado. Foi postulado que a suplementação com $\omega$-3 pode ter estimulado um passo no transporte reverso do colesterol, provavelmente pelo aumento do receptor scanvenger classe B-1 (observada no grupo suplementado).

No presente estudo, com o protocolo de $0,5 \mathrm{~g} / \mathrm{kg} / \mathrm{dia}$ foi verificado um aumento significativo nas concentrações plasmáticas de HDL somente nos grupos controle e controle+nado. Já no protocolo de $1,0 \mathrm{~g} / \mathrm{kg} / \mathrm{dia}$, observou-se uma redução nas concentrações de HDL nos animais de todos os grupos experimentais, mas a redução mais significante ocorreu nos animais do grupo que recebeu somente $\omega$-3 e não foi submetido ao nado $(p<0,0001)$. Destaca-se que, quando a suplementação de $\omega$-3 foi associada ao nado, observouse uma menor redução do que no grupo $\omega$-3 $(p=0,0156)$. De acordo com os resultados, os grupos que receberam $\omega-3$ por gavagem mantiveram ou reduziram significantemente as concentrações plasmáticas de HDL.

Em estudo de Jorge et al. ${ }^{13}$ não foram observadas modificações nas concentrações plasmáticas de HDL, quando coelhos hipercolesterolêmicos foram suplementados com $300 \mathrm{mg} / \mathrm{kg} / \mathrm{dia}$ de $\omega$-3 e comparados aos não suplementados.

Os efeitos dos $\omega$-3 sobre os lipídeos e as lipoproteínas plasmáticas têm sido contraditórios, existindo uma grande variabilidade de resultados entre os diferentes estudos, possivelmente em razão de diferentes desenhos experimentais e doses utilizadas.

As doses de $\omega-3$, utilizadas em testes com animais, são geralmente consideradas excessivas quando comparadas às quantidades consumidas por seres humanos. Além disso, a ingestão elevada de $\omega$-3 pode causar desconforto gastrointestinal, além de sensação desagradável de gosto de peixe após o uso ${ }^{4}$. No presente estudo, as doses foram elevadas, considerando-se que a de 1,0 $/ \mathrm{kg} / \mathrm{dia}$ corresponderia a $70 \mathrm{~g} /$ dia de $\omega$-3 para um homem de $70 \mathrm{~kg}$, e que $0,5 \mathrm{~g} / \mathrm{kg} / \mathrm{dia}$ de $\omega$-3, equivaleria a $35 \mathrm{~g} /$ dia de $\omega$-3 para o mesmo indivíduo.

A suplementação com o $\omega-3$ nas doses utilizadas $(0,5$ e 1,0 g/ $/ \mathrm{kg} / \mathrm{dia})$ parece ser benéfica nas concentrações plasmáticas de colesterol total e triglicerídeos em ratos, especialmente quando associada ao nado, mas pesquisas posteriores poderão auxiliar na compreensão da relação da ingestão de óleo de peixe com as concentrações de lipídeos sangüíneos. 
Sugere-se ainda que sejam estudados os efeitos da suplementação de pequenas doses de $\omega$-3 no metabolismo lipídico e na adiposidade de ratos submetidos a dietas normolipídicas com diferentes tipos de ácidos graxos (dietas isoenergéticas), bem como sua interação com a prática regular de diferentes tipos e intensidades de exercícios físicos. Esses estudos poderiam ser relacionados, posteriormente, com uma eventual recomendação de ingestão de $\omega$-3 provenientes dos alimentos, em benefício da saúde humana.

\section{COLABORADORES}

B. MORITZ responsável pela redação e pela pesquisa. E. WAZLAWIK orientadora do trabalho. J. MINATTI e R.C. DIMBARRE DE MIRANDA auxiliaram na execução da pesquisa.

\section{REFERÊ N CIAS}

1. Pellizzon M, Buison A, Ordiz F, Santa Ana L, Jen C. Effects of dietary fatty acids and exercise on bodyweight regulation and metabolism in rats. Obesity Res. 2002; 10(9):947-55.

2. Aguila $M B$, Loureiro $C C$, Pinheiro $A R$, Mandarimde-Lacerda CA. Lipid metabolism in rats fed diets containing different types of lipids. Arq Bras Cardiol. 2002; 78(1):32-8.

3. Gaíva MH, Couto RC, Oyama LM, Couto GEC, Silveira VLF, Ribeiro EB, et al. Diets rich in polyunsaturated fatty acids: effect on hepatic metabolism in rats. Nutrition. 2003; 19(2):144-9.

4. Covington MB. Omega-3 fatty acids. Am Fam Physicion. 2004; 70(1):133-40.

5. Águila MB, Apfel MIR, Mandarin-de-Lacerda CA. Comparação morfológica e bioquímica entre ratos envelhecidos alimentados com dieta hiperlipídica e com óleo de canola. Arq Bras Cardiol. 1997; 68(3):155-61.

6. Lombardo YB, Chicco AG. Effects of dietary polyunsaturated n-3 fatty acids on dislipidemia and insulin resistance in rodents and humans. A review. J Nutr Biochem. 2006; 17(1):1-13.

7. Lima FEL, Menezes TN, Tavares MP, Szarfarc SC, Fisberg RM. Ácidos graxos e doenças cardiovasculares: uma revisão. Rev Nutr. 2000; 13(2):73-80.

8. Baró L, Fonollá J, Peña JL, Martinez-Férez A, Lucena A, Jiménez J, et al. N-3 fatty acids plus oleic acid and vitamin supplemented milk consumption reduces total and LDL cholesterol, homocysteine and levels of endothelial adhesion molecules in healthy humans. Clin Nutr. 2003; 22(2):175-82.

9. Hu FB, Stampfer MJ, Manson JE, Rimm EB, Wolk A, Colditz GA, et al. Dietary intake of a-linolenic acid and risk of fatal ischemic heart disease among women. Am J Clin Nutr. 1999; 69(5):890-7.

10. Carvajal O, Ângulo O. Effect of n-3 polyunsaturated fatty acids on the lipidic profile of healthy Mexican volunteers. Salud Publica Mex. 1997; 39(3):221-4.

11. Pellizzon M, Buison A, Ordiz F, Santa Ana L, Jen C. Effects of dietary fatty acids and exercise on bodyweight regulation and metabolism in rats. Obes Res. 2002; 10(9):947-55.

12. Laidlaw M, Holub BJ. Effects of supplementation with fish oil-derived $n-3$ fatty acids and $y$-linolenic on circulating plasma lipids and fatty acid profiles in women. Am J Clin Nutr. 2003; 77(1):37-42.

13. Jorge PAR, Neyra LC, Ozaki RM, Almeida E. Efeito dos ácidos graxos ômega-3 sobre o relaxamentodependente do endotélio em coelhos hipercolesterolêmicos. Arq Bras Cardiol. 1997; 69(1):13-8.

14. Durant RH, Linder CW, Mahoney OM. Relationship between habitual physical activity and serum lipoprotein levels in white male adolescents. J Adolesc Health Care. 1983; 4(4):235-40.

15. Kiran TR, Subramanyam MVV, Devi SA. Swim exercise training and adaptations in the antioxidant defense system of myocardium of old rats: relationship to swim intensity and duration. Comp Biochem Physiol Biochem Mol Biol. 2004; 137(2):187-96.

16. Guedes DP, Guedes JERP. Physical activity, cardiorespiratory fitness, dietary content and risk factors that cause a predisposition towards cardiovascular disease. Arq Bras Cardiol. 2001; 77(3):251-7.

17. Porsolt RD, Le Pichon $M$, Jafre $M$. Depression: a new animal model sensitive to antidepressant treatments. Nature. 1977; 266(5604):730-2.

18. Devi SA, Prathima S, Subramanyam MVV. Dietary vitamin $\mathrm{E}$ and physical exercise: I. altered endurance capacity and plasma lipid profile in ageing rats. Exp Gerontol. 2003; 38(3):285-90.

19. Morvan V, Dumon MF, Palos-Pinto A, Bérard AM. $\mathrm{N}-3$ FA increase liver uptake of HDL-cholesterol in mice. Lipids. 2002; 37(8):763-72.

20. Arteaga A, Villanueva CL, Skorin C, Guasch V, Ovando FS, Velasco N, et al. Dislipidemicos con cardiopatia coronaria. Effecto de diferentes dosis de acidos grasos omega 3 sobre los lipidos y lipoproteinas sericas. Rev Méd Chile. 1993; 121(6): 618-25. 
21. Eristland J. Safety considerations of polyunsaturated fatty acids. Am J Clin Nutr. 2000; 71(Supll 1): 197S-201S.

22. Harris WS, Lu G, Rambjor GS, Walen Al, Ontko JA, Cheng $Q$, et al. Influence of $n-3$ fatty acid supplementation on the endogenous activities of plasma lipases. Am J Clin Nutr. 1997; 66(2): 254-60.

23. Park Y, Harris WS. Omega-3 fatty acid supplementation accelerates chylomicron triglyceride clearance. J Lipid Res. 2003; 44(3): 455-63.

24. Prinsen BHCMT, Romijn JA, Bisschop $\mathrm{PH}$, Barse MMJ, Barrett PHR, Ackermans M, et al. Endogenous cholesterol synthesis is associated with VLDL-2 apoB-100 production in healthy humans. J Lipid Res. 2003; 44(7):1341-8.

25. Pan M, Cederbaum Al, Zhang Y, Ginsberg HN, Willians KJ, Fisher EA. Lipid peroxidation and oxidant stress regulate hepatic apolipoprotein B rdegradation and VLDL production. J Clin Invest. 2004; 113(9):1277-87.
26. Stocker R, Keaney JF. Role of oxidative modifications in atherosclerosis. Physiol Rev. 2004; 84(4): 1381-478.

27. Kikugawa K, Yasuhara Y, Ando K, Koyama K, Hiramoto K, Suzuki M. Effect of supplementation of $n-3$ polyunsaturated fatty acids on oxidative stress-induced DNA damage of rat hepatocytes. Biol Pharm Bull. 2003; 26(9):1239-44.

28. Song JH, Fujimoto KE, Miyazawa T. Polyunsaturated (n-3) fatty acids susceptible to peroxidation are increased in plasma and tissue lipids of rats fed docosahexaenoic acid-containing oils. J Nutr. 2000; 130(12):3028-33.

29. Mata P, Alonso R, Mata N. Los Omega-3 y omega9 en la enfermedad cardiovascular. In: Mataix J, Gil A. Libro blanco de los omega-3. Madrid: Instituto Omega-3; 2002. p.49-62.

Recebido em: 13/3/2007

Versão final reapresentada em: 22/4/2008 Aprovado em: 29/9/2009 